$\Delta$ Palabras clave/ Territorio, paisaje, identidad, cultura Mapuche.

$\Delta$ Keywords/ Territory, landscape, identity, Mapuche culture.

$\Delta$ Recepción/ 16 mayo 2018

$\Delta$ Aceptación/ 14 enero 2019

\title{
El territorio como recurso
}

para la revalorización del paisaje cultural Mapuche. Comuna de Arauco, VIII Región del Bío-Bío, Chile.

\section{Territory as a Resource to Revalorize the} Mapuche Cultural Landscape. Commune of Arauco, Bío-Bío Region, Chile.

\author{
Katherine Muñoz \\ Arquitecta, Universidad Nacional Andrés Bello, \\ Chile. \\ munozrojas.katherine@gmail.com \\ Susana López \\ Docente, Universidad Peruana de Ciencias \\ Aplicadas, Perú \\ Arquitecta, Universidade de A Coruña, España \\ Doctora en Urbanismo y Ordenación del \\ Territorio, Universidad Politécnica de Cataluña \\ (UPC), España \\ European Postgraduate Master in Urbanism, \\ UPC, España, y Technische Universiteit Delft \\ Holanda. \\ pcarslop@upc.edu.pe
}

RESUMEN/ El pueblo mapuche ha sufrido a lo largo de su historia un continuo proceso de usurpación. La apropiación de sus territorios ancestrales y la expansión indiscriminada de las plantaciones forestales han ocasionado una serie de problemáticas que han desvinculado a dicho pueblo de su territorio natural, desvalorizando así su identidad. Sin embargo, aún es posible apreciar un importante legado inmerso en el territorio, fruto de la acumulación y superposición de sucesos históricos, sociales y culturales, y que resulta esencial para sus comunidades. Reconocer la estructura cultural inserta en este territorio será fundamental para la revalorización del paisaje cultural mapuche. El presente estudio intentará por lo tanto, definir a partir de un caso de estudio determinado -la Comuna de Arauco- una serie de estrategias y acciones dirigidas a proteger, recuperar y revalorizar aquellos elementos que componen su paisaje cultural, con el objetivo de reivindicar y potenciar la identidad usurpada. ABSTRACT/ The Mapuche people have suffered sustained encroachment throughout history. The misappropriation of their ancestral lands and the wholesale expansion of forest plantations have caused multiple issues, resulting in their disconnection from their natural lands and the further downgrading of their identity. There is still a strong legacy embedded in their territory, however, resulting from the buildup and overlapping of historical, social and cultural events, all crucial for Mapuche communities. Acknowledging the cultural arrangements entrenched in that territory will be critical for the revalorization of the Mapuche cultural landscape. Based on a specific case study -the Commune of Arauco- this work attempts to define several strategies and actions aimed at protecting. recovering and revalorizing the elements that make up the Mapuche cultural landscape in order to assert and reinforce their usurped identity.

\section{INTRODUCCIÓN.}

\section{Pérdida de identidad territorial ante} la apropiación de los territorios

\section{indígenas. La pérdida de identidad del}

pueblo Mapuche se debe, en gran medida, al proceso de usurpación territorial que ha sufrido a lo largo de su historia. Un hecho que se remonta a la conquista de la Corona Española y que continúa a mediados del siglo XIX con la vocación expansionista del Estado de Chile, que tras la primera crisis económica de su modelo de exportación de materias primas (1857-1861), manifestó un interés inmediato en relación a los territorios ubicados al sur de la frontera del Bío-Bío. El gran potencial agrícola y la mano de obra barata hacían que la tierra araucana comenzara a ser vista como una zona de potencial riqueza para crear lazos con el mercado argentino (Pinto 1992).

Sin embargo, la usurpación del territorio mapuche se consolidó como consecuencia de la aprobación de dos edictos: la Ley de 2 de julio de 1852 y el Decreto Ley №701 de 1974. El primero estableció la creación de la Provincia de Arauco en los territorios comprendidos desde el Bío-Bío al Toltén, estableciendo así una estrategia de apropiación administrativa (Bonet 2014). Para ello, autorizaba al presidente de la República a "dictar las ordenanzas que juzgue convenientes para el mejor gobierno de la frontera, para la más eficaz protección de los indígenas, para promover su más pronta civilización y para arreglar los contratos y relaciones de comercio con ellos" (Aylwin 1995). El segundo, implantó un nuevo modelo económico de explotación agrícola, que aún continúa 


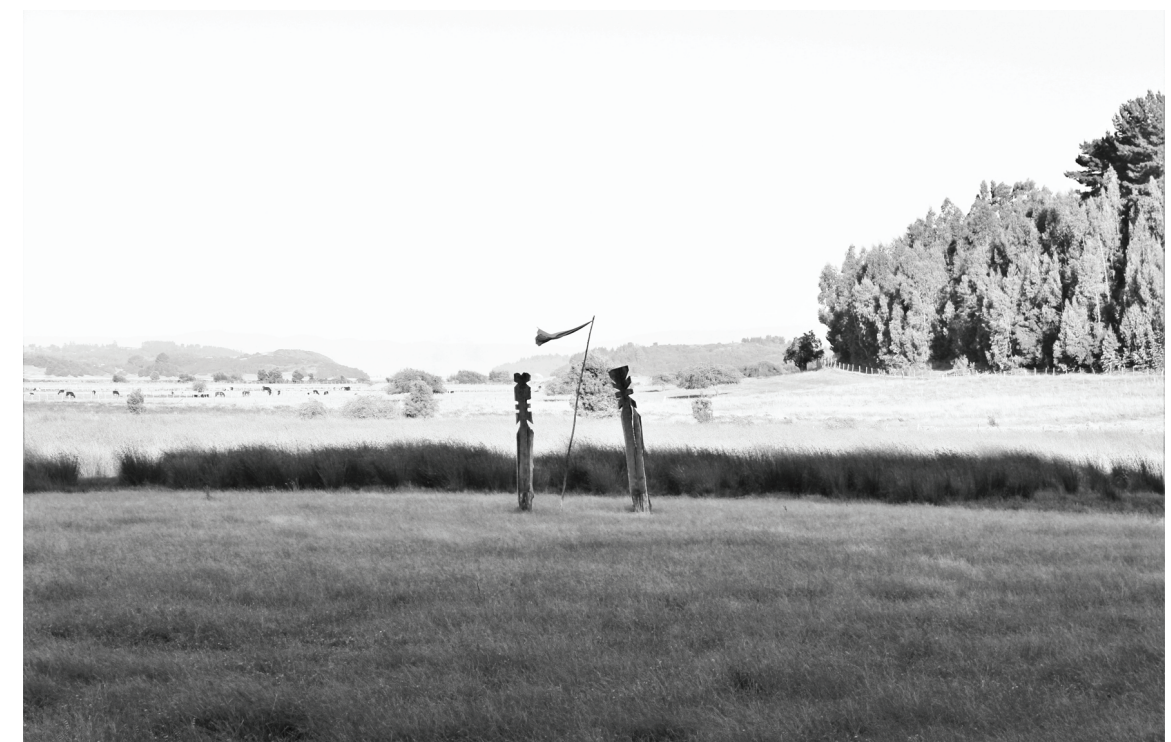

Imagen 1. Paisaje cultural mapuche. Chemamull ubicados en Agua Pié, Arauco (fuente: Las autoras 2016).

vigente hasta nuestros días: la industria forestal (Frías 2003; Calbucura y Le Bonniec 2009). Su establecimiento trajo consigo no solo la pérdida ambiental derivada de la degradación del bosque nativo en favor de la plantación masiva de especies exógenas ocupando una superficie aproximada de tres millones de hectáreas (Corporación Naciona Forestal - CONAF 2013)-, sino también un enorme impacto en la calidad de vida de las comunidades mapuche.

Este escenario, caracterizado por la falta de tierras y oportunidades laborales, ha fomentado el desplazamiento masivo de un importante porcentaje de su población hacia los principales centros urbanos (Montalba, Carrasco y Araya 2005), en lo que ha sido entendido por Imilan (2008) como una "necesidad urgente de sobrevivencia, que no sólo supuso su expulsión en términos de residencia, sino también, en muchos casos, de la pertenencia a la comunidad" (27) Sin embargo, en un contexto donde "el reasentamiento, traslado o erradicación, no permite opción alguna de continuidad identitaria y cultural, pues la asociación tierra-hombre es el lazo que permite la existencia del pueblo mapuche, y por lo tanto, el traslado de un hábitat a otro equivale al etnocidio" (Comisión Nacional del Medio Ambiente - CONAMA 1997) aún es posible apreciar un importante legado de interés histórico, natural, social y cultural inmerso en el territorio araucano, cuyo paisaje, a pesar de ser asolado por las plantaciones forestales, deja entrever las huellas de una serie de elementos esenciales para las comunidades.

Nos referiremos por ende a un territorio, que entendido desde la perspectiva indígena, comprende una dimensión espacial ligada a una dimensión relacional, donde el vínculo entre el mapuche y su tierra es su elemento identitario fundamental, ya que la proyección de una vida en torno a ella es la base de su desarrollo como cultura (Ibarra 2008). En ese sentido, teniendo en cuenta que el territorio se presenta como un espacio geográfico atribuido a la comunidad humana que lo ocupa, además de ser el principal recurso material cargado de múltiples atribuciones culturales (Zoido 2008), y que el paisaje se entiende como "un magno documento territorial, una herencia transmitida a lo largo del tiempo y memoria de cada lugar" (Schama 1995), o "un constructo que los hombres realizamos a través de los fenómenos de la cultura" (Maderuelo 2005), podemos afirmar que el paisaje es una seña de identidad territorial (Hernández 2009), un contenedor de la memoria (Stephens 2002) resultado de la interacción entre el entorno, las poblaciones que lo habitan y los significados que se le asocian (Naveh 2000); identidad que se hace explícita en la materialidad de cada paisaje y en sus representaciones sociales $y$ culturales (Mata 2008).

Bajo esta premisa se considera entonces, que la identidad mapuche podrá resignificarse cuando sus comunidades puedan volver a dotar a su espacio de un significado socio-cultural, siendo el paisaje el soporte de dicha identidad.

El presente estudio intentará definir, a partir de un caso de estudio determinado -la Comuna de Arauco-, una serie de estrategias y acciones dirigidas a proteger, recuperar y revalorizar aquellos elementos que componen su paisaje cultural, para así reivindicar y potenciar la identidad usurpada. 


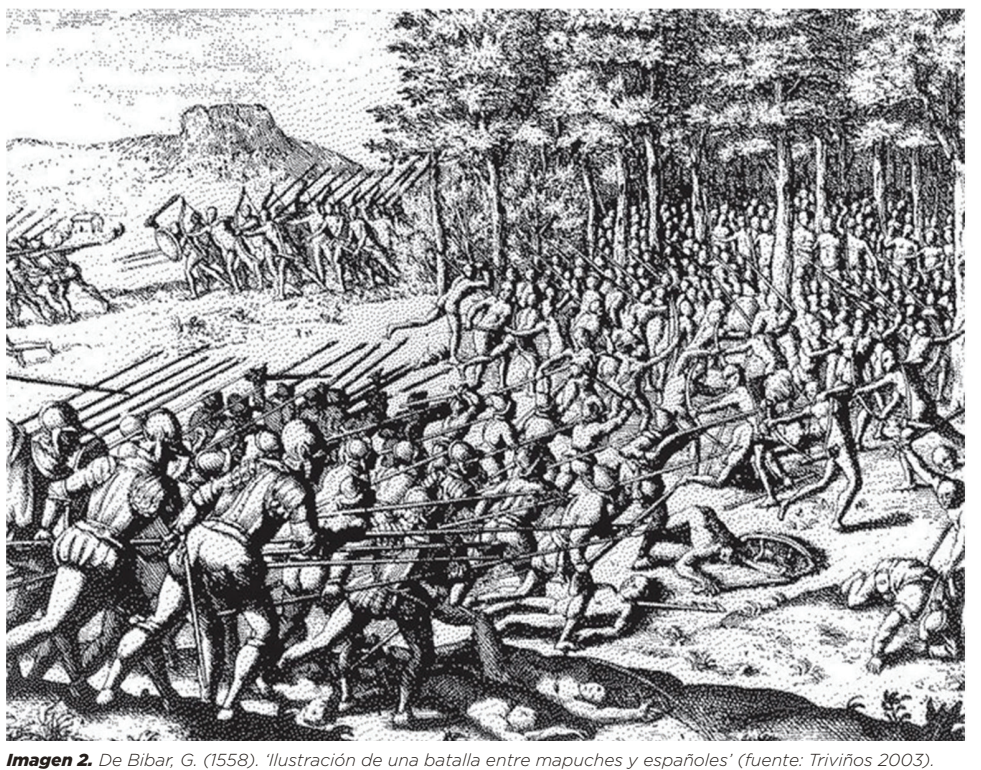

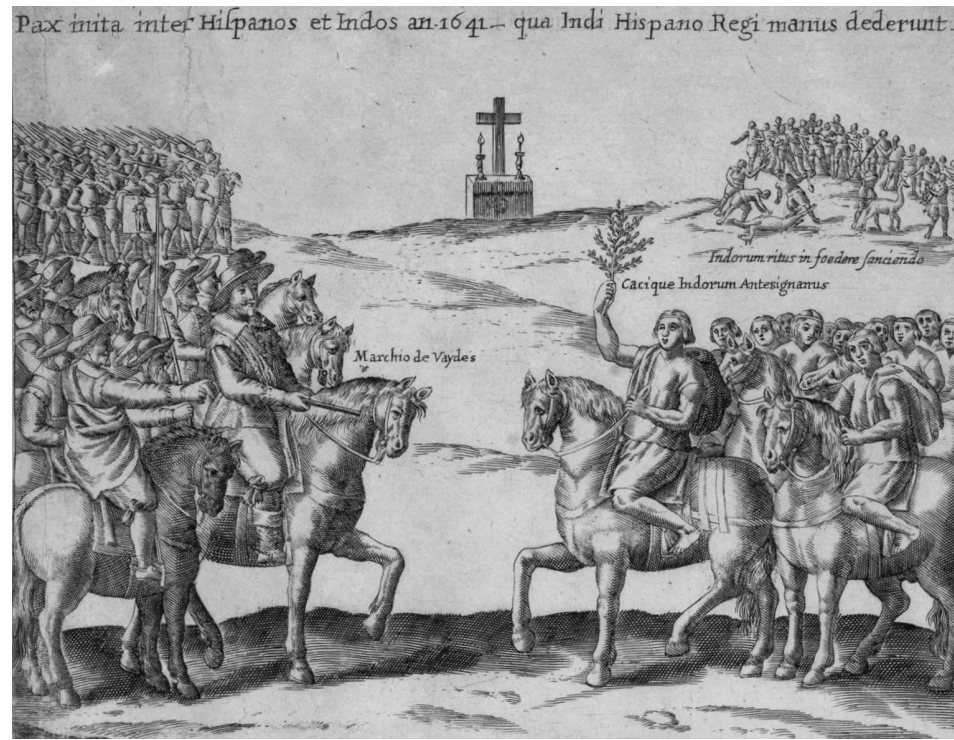

Imagen 3. De Ovalle, A. (1641). 'I/ustración del Parlamento de Quilín entre hispanos e
CASO.

El territorio de Arauco como escenario histórico, cultural y paisajístico. A pesar de que la región

del Bío-Bío concentra tan solo un $8,8 \%$ del total de la población mapuche del país (Instituto Nacional de Estadísticas - INE 2003), se ha considerado interesante abordar la Comuna de Arauco como caso de estudio, pues es un ejemplo irrefutable de las consecuencias históricas, culturales y paisajísticas del conflicto y apropiación del territorio mapuche.

Si nos remontamos al siglo XVI, la Guerra de Arauco (1550-1656) fue un período donde tuvieron lugar importantes enfrentamientos suscitados por la resistencia de la población mapuche ante la ocupación indiscriminada de sus tierras (Jara 1971) (imagen 2). Es aquí donde se impulsó el despliegue de la primera línea fronteriza entre la zona de dominación española y el territorio autónomo mapuche (Bonet 2014). El tratado de paz emanado en las Paces de Quilín por parte de España y la Capitanía General de Chile (imagen 3) reconoce formalmente la independencia de los territorios comprendidos entre el río Bío-Bío y el río Toltén (Bengoa 1996), creando sus propias estructuras de gobernabilidad basadas en el az mapu, costumbres y leyes consuetudinarias propias del pueblo mapuche (Bonet 2014) Esta situación se revierte, sin embargo, después de la masiva ocupación militar por parte del Estado chileno (Gavilán 2002). La Pacificación de la Araucanía (1860-1883) supuso un nuevo período de enfrentamientos, que tuvieron como consecuencia el avance en la ocupación de los territorios indígenas. La entrega en aquel entonces de Títulos de Merced, no solo significó el inicio de una reducción política, cultural y económica del pueblo mapuche, la cual se acentuaría en el siglo XX marcando el fin de su independencia y el comienzo de su colonización (Calbucura y Le Bonniec 2009), sino también la alteración de la relación de los mapuche con sus tierras, territorios y recursos naturales (Aylwin 2002).

Asimismo, el proceso de contrarreforma agraria instaurado bajo el régimen militar, además de provocar el desplazamiento de 4.879 personas en la Provincia de Arauco, de las cuales 1.962 corresponden a la Comuna de Arauco (INE 2003), supuso la pérdida de 60.000 hectáreas de bosque nativo (Aylwin 2000). A esto cabe sumar la privatización de más de dos millones de hectáreas de plantaciones de pino y eucaliptos que se encuentran en conflicto con reservas mapuche

(Calbucura y Le Bonniec 2009), forzando a sus comunidades a tener que establecer acuerdos con las empresas forestales para respetar, de esa manera, el acceso a sus antiguas tierras (Lincopi 2016). Todo ello ha provocado que hoy, los lugares y vestigios mapuche se encuentren inmersos en un paisaje degradado, lo que ha producido un cambio en la manera en que los mapuche se relacionan con sus tierras.

Se puede afirmar entonces, que la usurpación y degradación de la Comuna de Arauco, sumada a la desvalorización de los sitios de significación cultural mapuche, han generado una desvinculación de ese pueblo con su territorio, y por tanto, una desvalorización de su propia identidad. 
Sin embargo, y aunque no existen documentos legales que reconozcan la propiedad mapuche en esta comuna, aún es posible obtener evidencias concretas que demuestran una antigua ocupación indígena (figura 1). El territorio se concibe por tanto, como una compleja red de sitios e hitos geográficos, compuesta principalmente de viviendas, vestigios ceremoniales y lugares sagrados (Lincopi 2016), fundamento de una mirada donde alguna vez primaron las relaciones políticas, sociales, económicas, culturales y religiosas de estas comunidades. De este modo, si entendemos que el vínculo entre el territorio y la identidad de un pueblo es fundamental para el sustento de su paisaje cultural, entonces no será posible concebir un territorio sin su paisaje (Maderuelo 2010). Por ello, y ante un contexto caracterizado por la pérdida de autonomía, dominio e identidad, aparecen los siguientes interrogantes: ¿cómo se puede recuperar el paisaje y la identidad territorial del pueblo mapuche en el territorio de Arauco?, ¿cómo se puede poner en valor un paisaje cultural cuyos hitos más significativos han quedado inmersos en un contexto forestal?, ¿cuáles serán las acciones a seguir para revalorizar

\section{curales y sociales?}

\section{ESTRATEGIAS PARA EL RECONOCIMIENTO DEL PAISAJE CULTURAL MAPUCHE.}

Teniendo en cuenta que el paisaje es, en su configuración formal, la huella de la sociedad sobre la naturaleza, la marca o señal que imprime 'carácter' a cada territorio (Mata 2008), se considera necesario reposicionar la mirada mapuche en este paisaje desarraigado, explicitando las lógicas territoriales propias de su cultura frente a las lógicas de una cultura 'incorporada'. De esa manera, se podrá responder a las problemáticas reconocidas en el territorio araucano, así como establecer las estrategias de ordenación y revalorización pertinentes.

Tomando como referencia las palabras de Javier Maderuelo (2010) en su libro

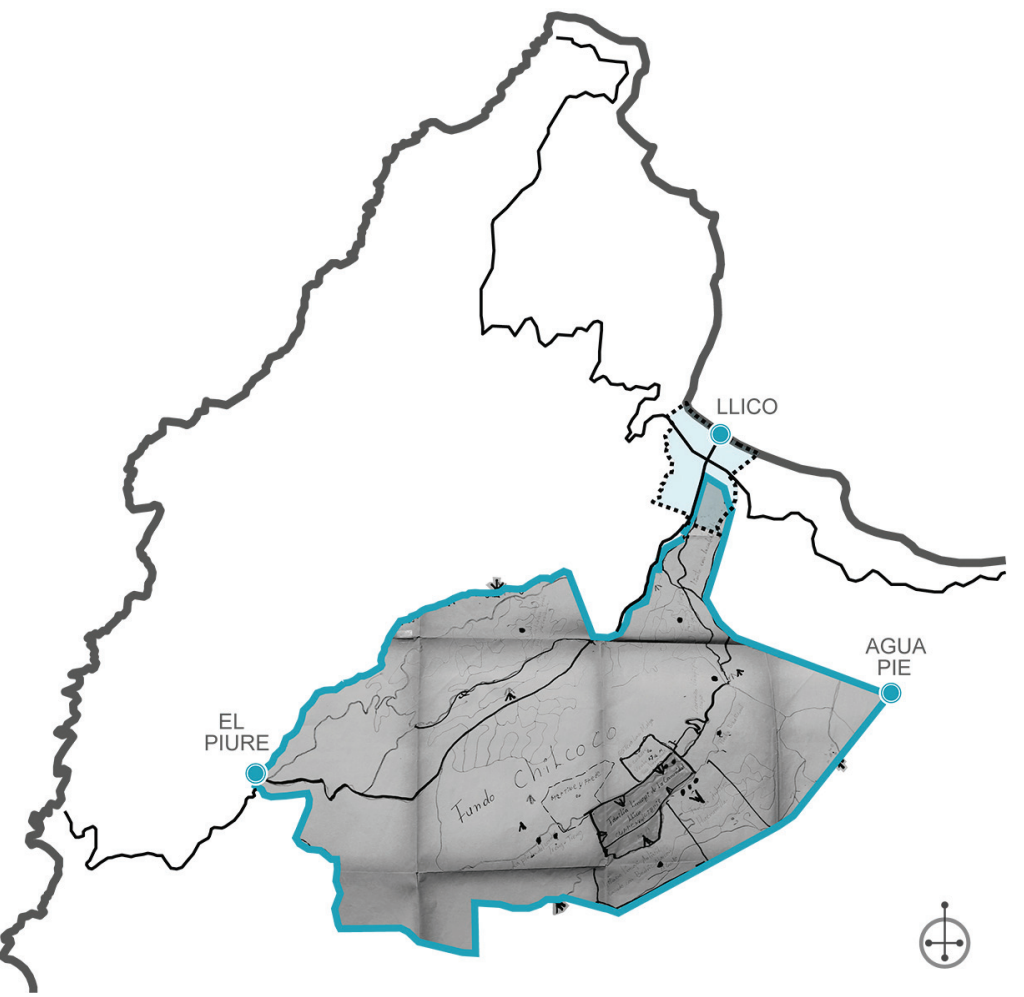

Figura 1. Plano de los territorios de propiedad indígena al interior del Fundo Chilkoko (fuente: Elaboración propia en base a Lincopi Figura

"Paisaje y Patrimonio", en donde "los hitos requieren intervenciones de integración en el paisaje para garantizar la interpretación del elemento patrimonial en el cuadro paisajístico que le da sentido" (17), el estudio tendrá como principal objetivo resignificar cada uno de los sitios ancestrales con carácter cultural y social que están comprendidos en el territorio (imagen 4), implementando medidas que permitan su recuperación, protección y revalorización. Para ello será necesario reconocer su cultura desde dos dimensiones o significados: la material, aquella que recoge los elementos culturales tangibles -rucas e hitos sagrados- (imagen 5); y la simbólica, que engloba aquellos actos intangibles -ritos y ceremonias mapuche-, donde toma importancia la conexión espiritual entre el hombre y su naturaleza para la realización de sus rogativas. El reconocimiento de estas dos dimensiones nos permitirá comprender la influencia que dicha cultura tiene con respecto al paisaje como legado para su comunidad.

Se desarrollará entonces una 'red de relaciones', basada en la contemplación y apreciación de los recursos culturales mapuche de la Comuna de Arauco. El objetivo es incitar al propio pueblo mapuche a potenciar su cultura, y por ende fortalecer su identidad territorial, al tiempo que se ofrece al resto de la sociedad la posibilidad de conocer, comprender y reconocer la importancia del paisaje y el significado de los recursos mapuche insertos en él. 


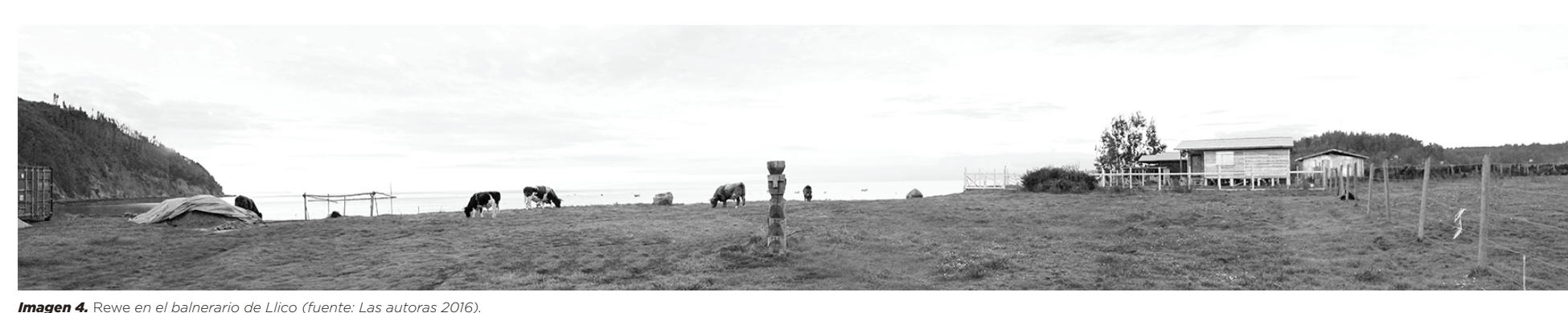

Imagen 4. Rewe en el balnerario de Llico (fuente: Las autoras 2016).

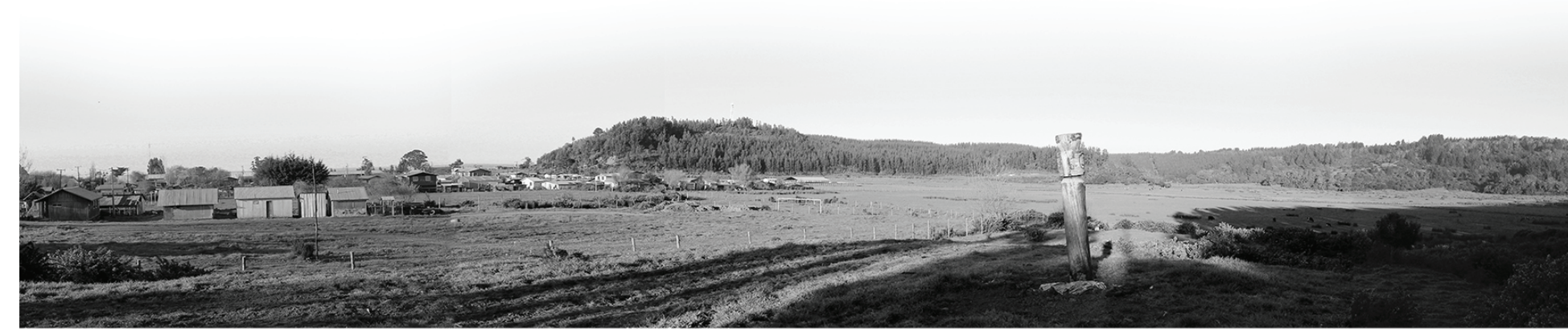

Imagen 5. Rewe a los pies del bosque forestal, Llico (fuente: Las autoras 2016).

METODOLOGÍA. El descubrimiento de los sitios y elementos de significación cultural fue posible gracias a la observación in situ del territorio araucano y la recopilación de información a través de reuniones y conversaciones con sus pobladores, abordando dos escalas de actuación: la Comuna de Arauco y la localidad de Llico. Se reunieron todos los antecedentes documentales y cartográficos que proporcionarían las claves culturales e identitarias del territorio mapuche, para luego corroborar la información recopilada con sus propios habitantes. Para tal fin, se realizaron entrevistas a diversos integrantes de las comunidades indígenas de la zona de Arauco: Llico, Tropen, Raqui Willi Mapu y Los Ñancos'. Sus experiencias personales no solo ayudaron a comprender físicamente el territorio y su paisaje, sino también el valor cultural que se encuentra inmerso en su geografía.

Asimismo, y considerando los antecedentes teóricos aportados, se procedió a realizar una serie de recorridos en el territorio. Esto, además de permitir reconocer la diferente naturaleza de los recursos identificados (natural, cultural e histórica), facilitó la comprensión de las relaciones y significados que dichos sitios tienen para la identidad del pueblo. Se trata de un hecho fundamental que ayudó a definir aquellos sectores estratégicos donde se implementarían las medidas enfocadas en la puesta en valor del territorio de Arauco.

Los entrevistados fueron: Clementina Lincopi, Luis Lincopi, Juan Rivas y Leonor Lincopi (Presidenta, Vicepresidente, Delegado y Participante de la Comunidad Indígena Llico); Luis Huenumilla y Paula Huenumilla (Presidente y Participante de la Comunidad Indigena Tropen); Eusebio Gayoso, Presidente de la Comunidad Indigena Raqui Willi Mapu; y Rolando Terán, Participante de la Comunidad Indígena Los Ñancos. 


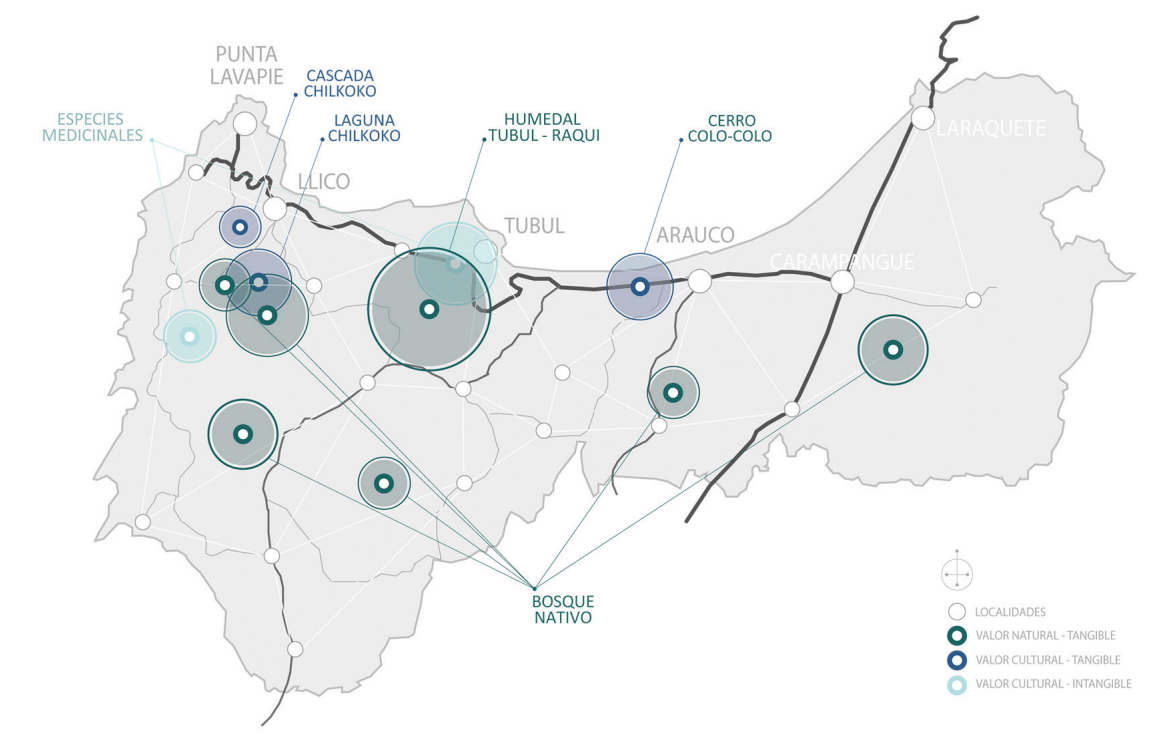

\section{ESCALAS DE ACTUACIÓN:} Comuna de Arauco.

En este contexto territorial se catastraron

los elementos culturales existentes,

clasificándolos en base a tres escenarios

(Busquets 2009): geográfico, entendido

como la representación de los elementos

naturales; territorial, aquel que engloba a

aquellos elementos que son utilizados como

recursos; y paisajístico, donde los elementos,

a través del enfoque socio-cultural,

adquieren una connotación simbólica

(figuras 2, 3 y 4 ).

Asimismo, estos tres escenarios se

catalogaron en siete 'expresiones' que recogen todos aquellos valores tangibles

e intangibles o 'hitos' dispuestos en el

territorio (Maderuelo 2010), ya sean

históricos, arqueológicos, evocativos,

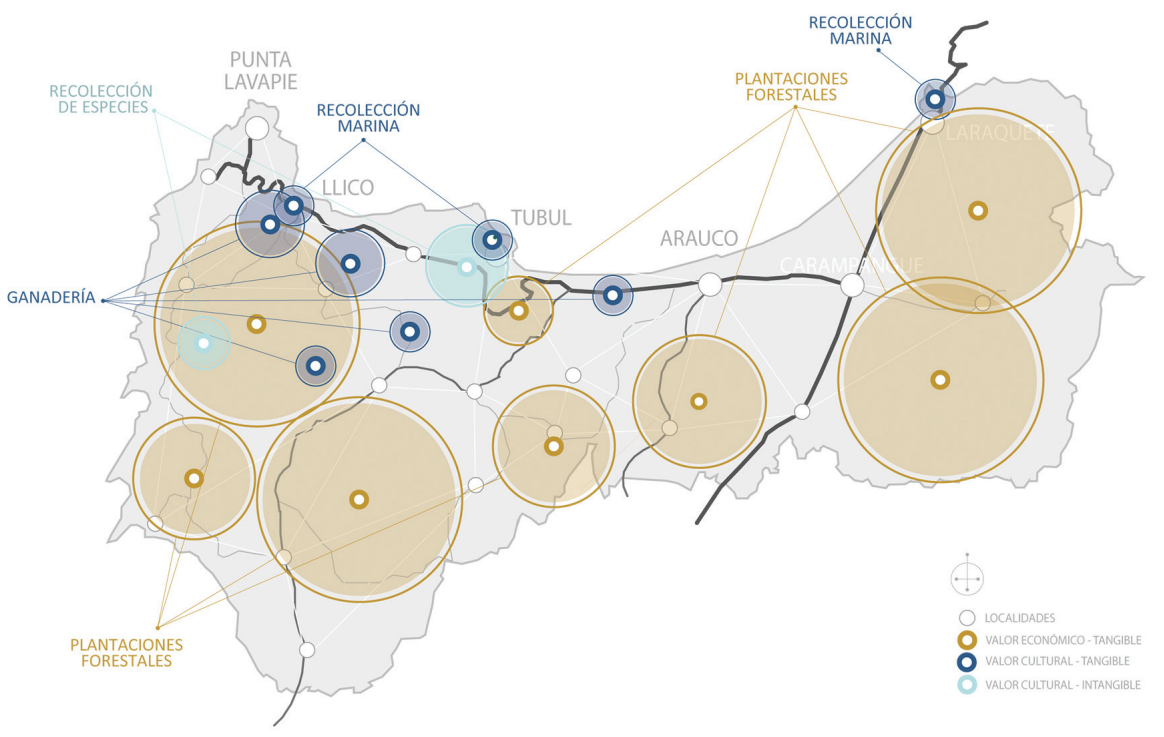

naturales, culturales, económicos y sociales.

Es en esta mirada conjunta de escenarios y expresiones donde se configura, finalmente, lo que entendemos como paisaje cultural.

La superposición de los tres escenarios geográfico, territorial y paisajístico-permite reconocer aquellas áreas estratégicas donde confluye la mayor cantidad de valores culturales presentes en el territorio, identificando en cada una de ellas aquel valor que destaca por sobre los demás. De esa forma, la localidad de Arauco manifiesta un valor histórico, por ser el sitio de inicio del conflicto mapuche; en Tubul predomina el valor natural, pues contiene sitios de gran significación ecológica -véase el caso del humedal Tubul-Raqui-; mientras que

Llico destaca por su valor cultural, ya que alberga gran cantidad de espacios sagrados dedicados a las rogativas mapuche (figura 5).

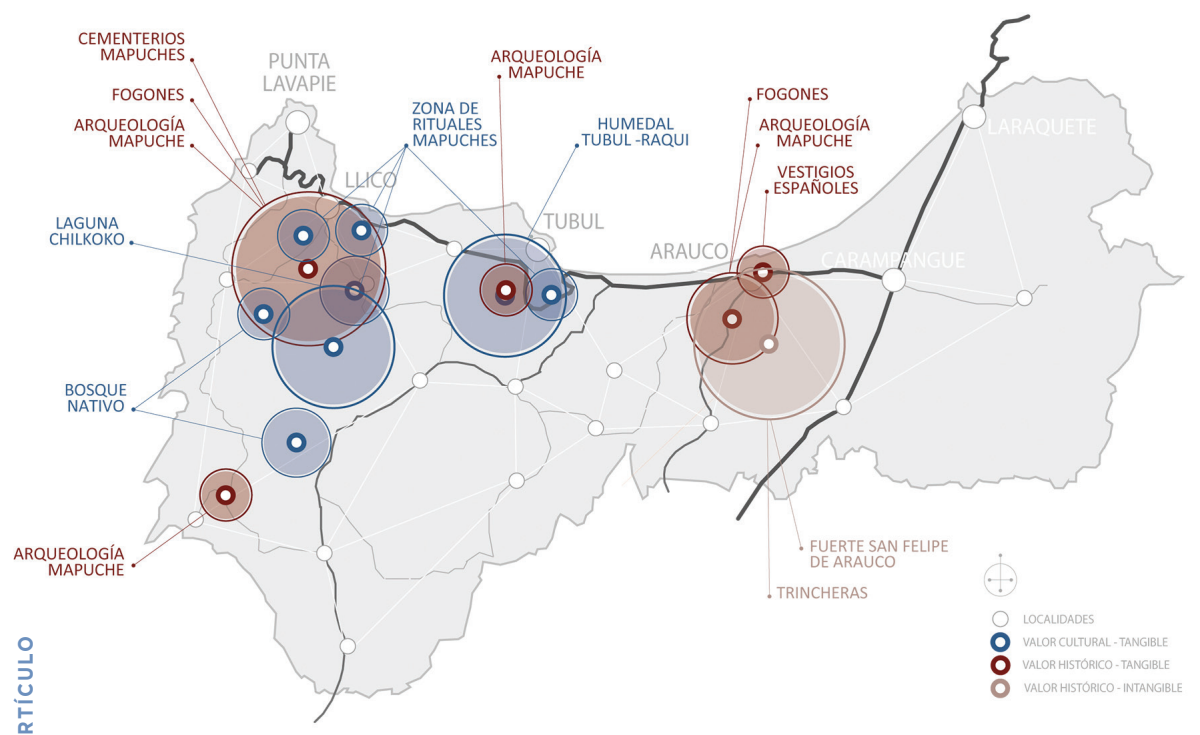

Es en esta última localidad donde

identificamos un mayor nivel de complejidad a la hora de comprender su estructura a nivel geográfico, territorial y paisajístico. Al valor cultural preponderante se suma un número significativo de valores naturales -ríos, lagunas, cerros y bosques nativos-, históricos - sitios cargados de historia con huellas visibles o no visibles de estos hechos-, y económicos -áreas de recolección, ganadería y plantaciones forestales. Llico se presenta entonces, como el sitio de mayor complejidad dentro de la Comuna de Arauco.

Figuras 2, 3 y 4. Escenario geográfico, territorial y paisajistico (fuente: Elaboración propia 2016). 


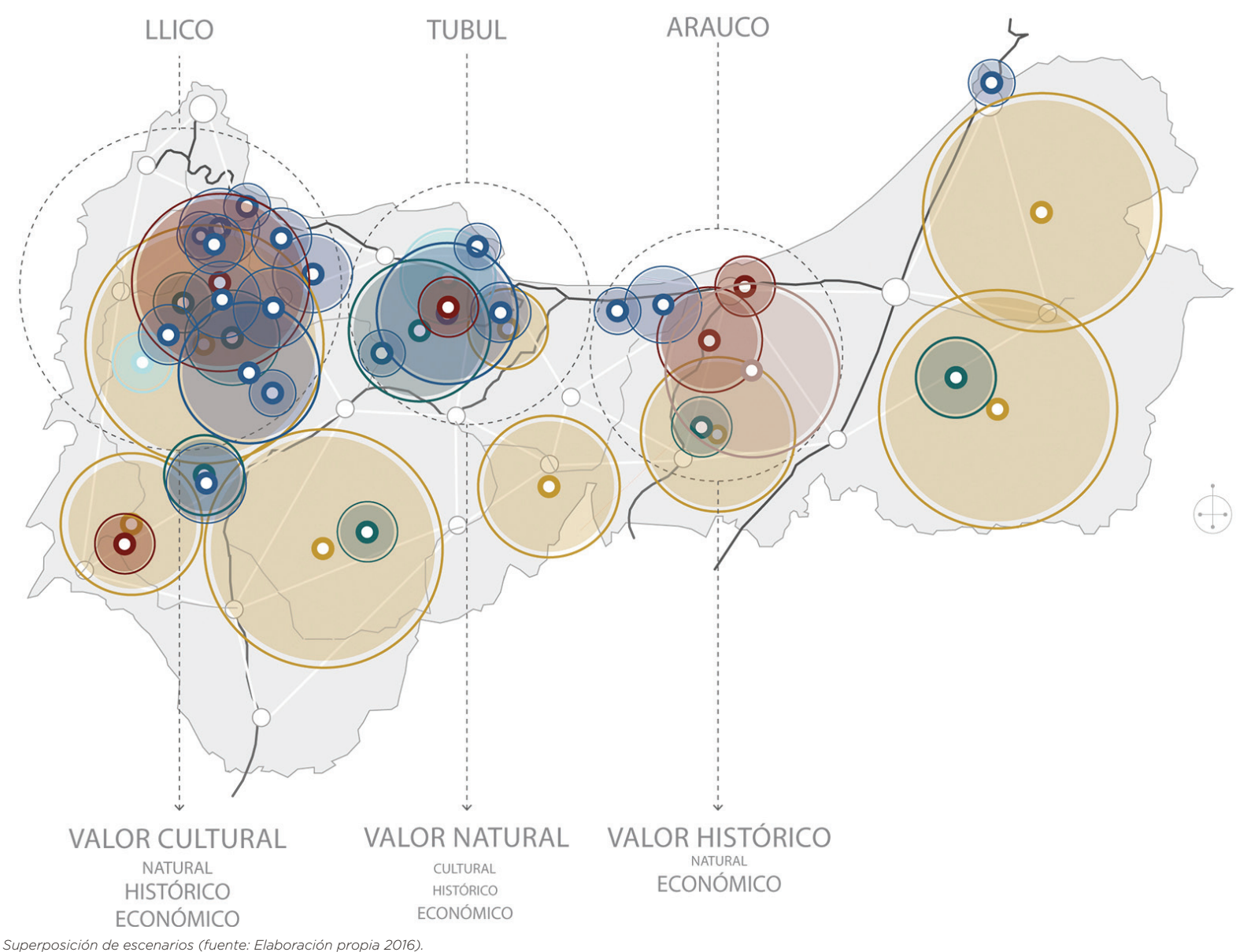

Figura 5. Superposición de escenarios (fuente: Elaboración propia 2016).

\section{Localidad de Llico, Fundo Chilcoco.}

La segunda aproximación territorial se enfoca en el Fundo Chilcoco, situado al sur de la localidad de Llico. Este lugar se caracteriza por ser un antiguo terreno indígena usurpado por el terrateniente Santiago Gaete Sierra, quien cedió el fundo años más tarde a la Universidad de Concepción, pero que en la actualidad es propiedad de la empresa Forestal Arauco (Iglesias y González 2013). En él, además de emplazarse una serie de sitios de recolección y extracción de recursos utilizados por las comunidades mapuche que habitaban antiguamente la zona, se asientan los sitios y elementos más significativos para estas comunidades: rukas (viviendas), rewes (estatuas de madera), chemamull (estatua de madera funerarias), treng-treng (cumbre del cerro Chilcoco), mankekura (piedra del cóndor), aliwen (árbol sagrado), chozlafquen (laguna amarilla), llawinkura (piedra bautismal), lafquen chilkoko (laguna Chilcoco) y trawun (sitio de reuniones). Este lugar se caracteriza entonces, por una importante lógica de relaciones respecto al quehacer mapuche -religión, economía, política- y al vínculo que existe entre esta sociedad y los recursos naturales, sagrados e históricos alli existentes.

La identificación y posterior superposición de una serie de capas temáticas no solo permite reconocer la disposición de su población, vialidad, recursos patrimoniales, hidrografía y vegetación nativa versus plantaciones forestales (figura 6), sino que pone en relieve la crítica situación en la que están los principales sitios de significación cultural, los cuales se encuentran reducidos a pequeñas secciones de tierra confinadas entre plantaciones de monocultivo.

Una vez identificado el carácter cultural que predomina en Llico, y reconocido cada uno de los sitios y elementos esenciales para el legado de la identidad mapuche, el siguiente paso fue implementar la segunda estrategia, donde se definen una serie de acciones enfocadas en la puesta en valor de la identidad territorial mapuche y su paisaje cultural. 

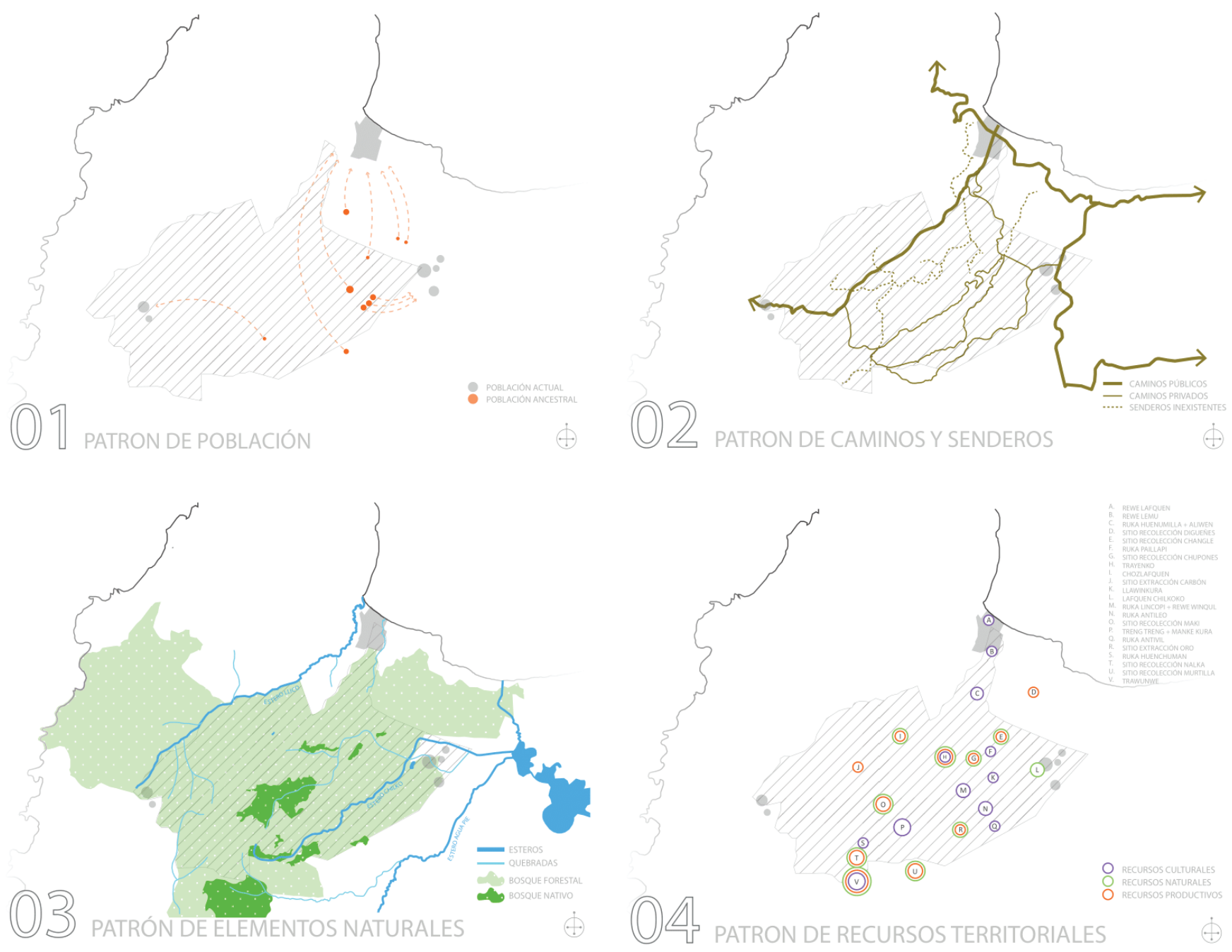

Figura 6. Capas temáticas (fuente: Elaboración propia 2016)

ACCIONES PARA LA REVALORIZACIÓN DEL PAISAJE CULTURAL MAPUCHE. Primera. "Puertas" en el territorio.

Como primera acción se determinó una serie de "puertas o nodos" que definen el acceso al territorio mapuche analizado. Estos puntos estratégicos se establecen a partir de cruces o convergencias de caminos, y están identificados por el traspaso de una estructura o de un carácter a otro (Lynch 1964). Su emplazamiento coincide con los tres principales núcleos poblados en torno al Fundo Chilcoco -Llico, Aguapie y Piures-, los cuales están vinculados a su correspondiente vía de comunicación.
La puerta principal se establece en Llico, mientras que en Aguapie y Piures se ubican las puertas secundarias; cada uno de estos nodos está dotado de pequeñas infraestructuras de servicios básicos y estacionamiento, permitiendo así recibir el flujo de visitantes e identificar su ingreso al territorio (figura 7 ).

Segunda. Recorridos. Como acción para leer y reconocer cada uno de los recursos identificados dentro del Fundo Chilcoco, se determinan una serie de recorridos, los cuales están apoyados en el sistema de vías y caminos existentes. Definir estas sendas permite organizar, relacionar y conectar cada uno de los elementos significativos o hitos (Lynch 1964), convirtiéndose de esa forma, en una guía para que el visitante comprenda el territorio. Las sendas a su vez, se dividen en principales y secundarias, dotando a cada una de ellas de una cualidad espacial que vendrá dada por la anchura o estrechez de su sección (figura 8).

Asimismo, estos recorridos se dividen en dos tipologías siguiendo una lógica de relaciones y usos diferentes. Por un lado, unos recorridos de uso público dirigidos al visitante o winka, determinados por aquellos caminos habilitados actualmente para uso y explotación forestal. 


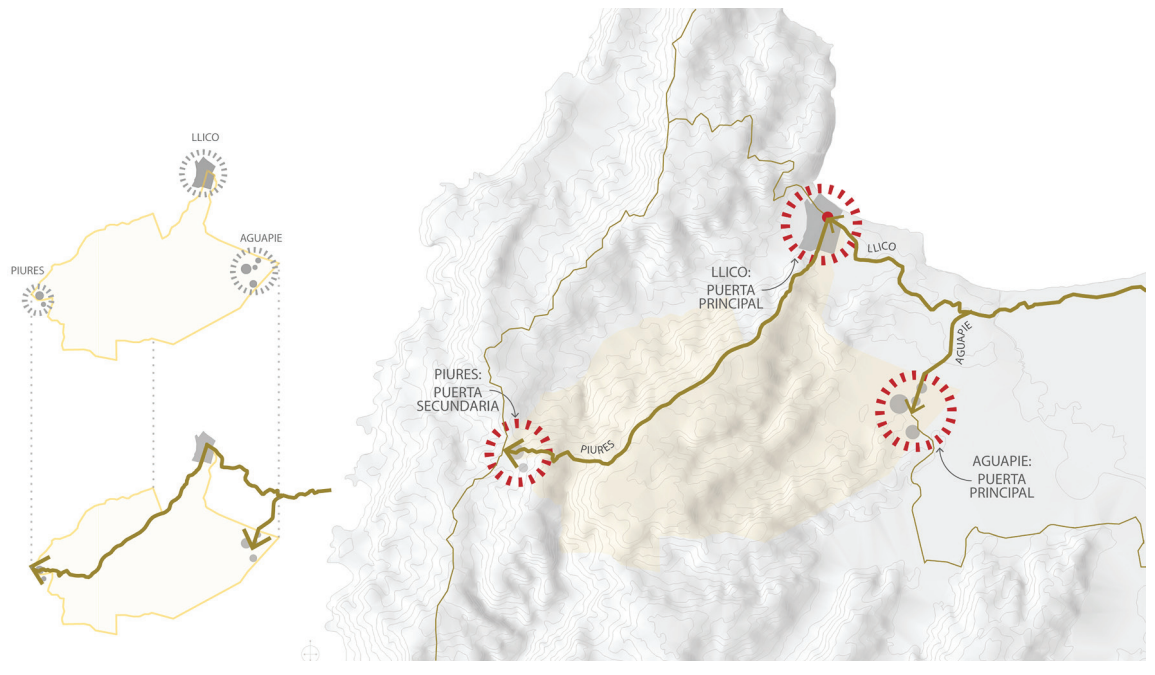

Figura 7. Puertas (fuente: Elaboración propia 2016)

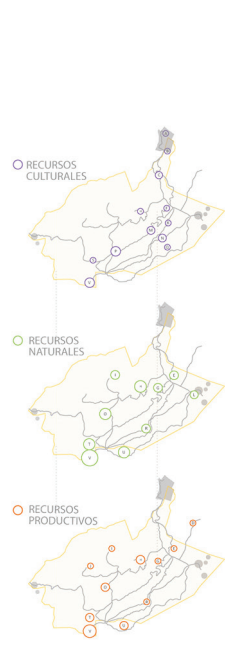

Figura 8. Recorridos (fuente: Elaboración propia 2016)

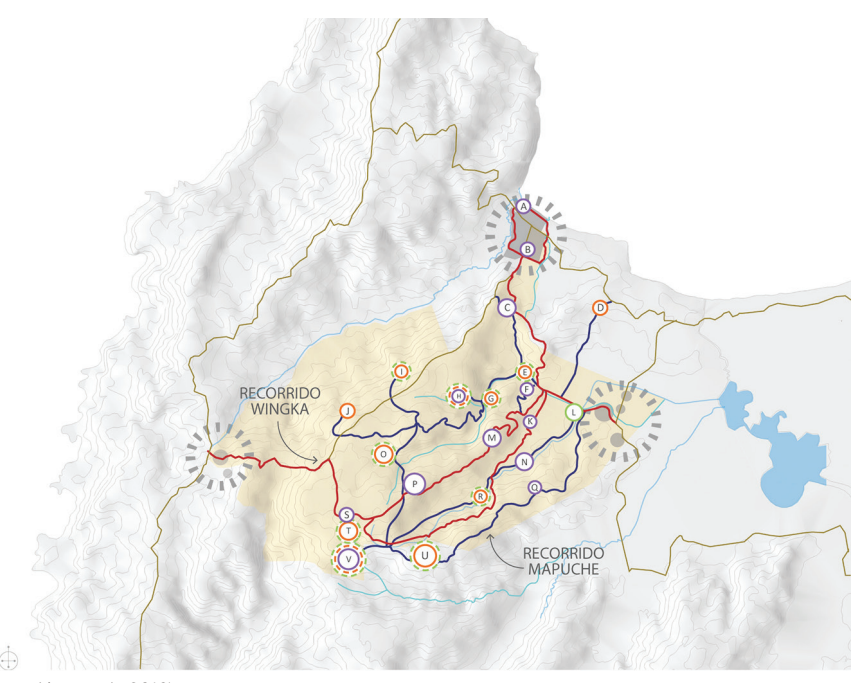

Por otro lado, unos recorridos privados dirigidos exclusivamente al uso de las comunidades mapuche; estos se establecen a partir de aquellos senderos cuya existencia aún es posible evidenciar, a pesar de haber sido prácticamente 'borrados' por la expansión indiscriminada de plantaciones forestales. Cada senda -winka y mapuchepodrá ser recorrida en diferentes tramos, permitiendo conocer los distintos elementos según su distancia, el modo de desplazamiento y el tiempo estimado que se desea utilizar para reconocer el territorio

\section{mapuche (figuras 9 y 10)}

\section{Tercera. Conservación y protección} del bosque nativo. Como acción

complementaria a las acciones antes propuestas, y que de alguna manera están dirigidas a promover la lectura del territorio mapuche, se considera necesario implementar medidas ambientales que ayuden a conservar y reforzar una identidad casi desaparecida pero que todavía subyace: el bosque nativo. La primera medida define una serie de áreas específicas de conservación ecológica en torno a aquellos pequeños mantos de bosque nativo que aún sobreviven entre las plantaciones. Estas áreas también engloban a todos aquellos hitos patrimoniales adyacentes que se encuentran diseminados entre el bosque exógeno. La segunda medida está enfocada hacia un proceso de re-naturalización de los antiguos senderos mapuche, cuya huella ha sido borrada por la ocupación forestal (figura 11) 


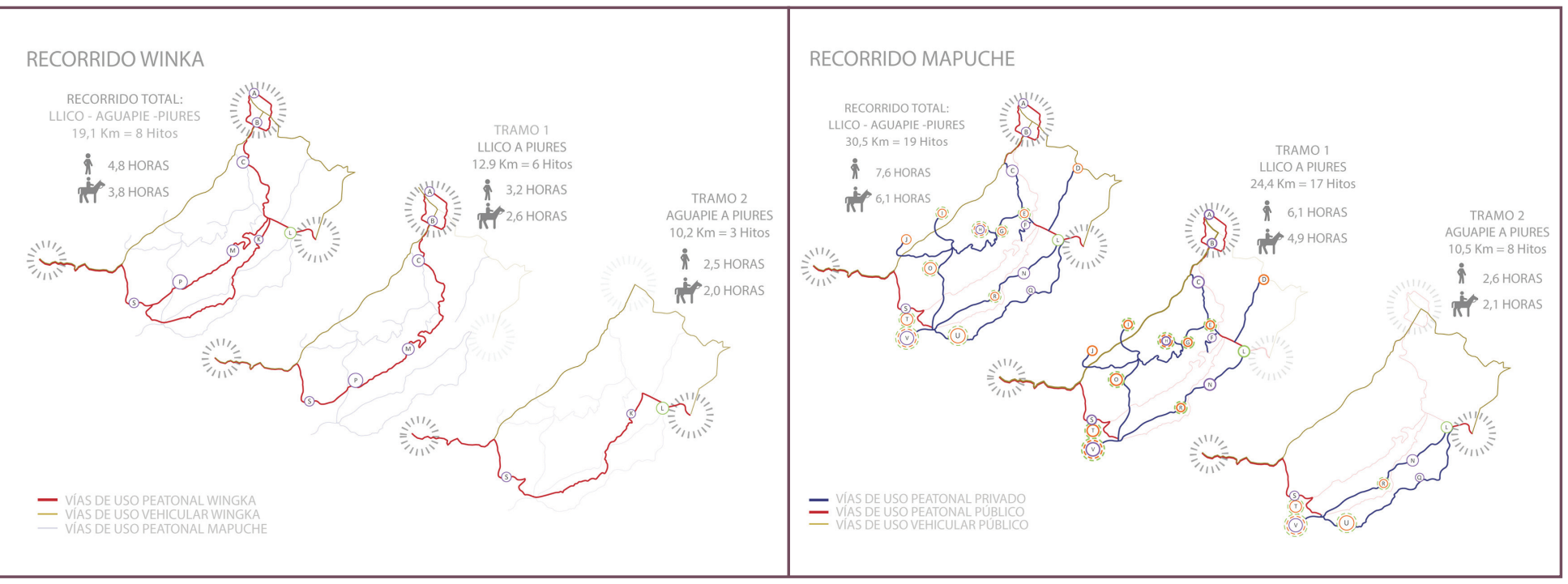

Figuras 9 y 10. Tipologías de recorridos (fuente: Elaboración propia 2016).

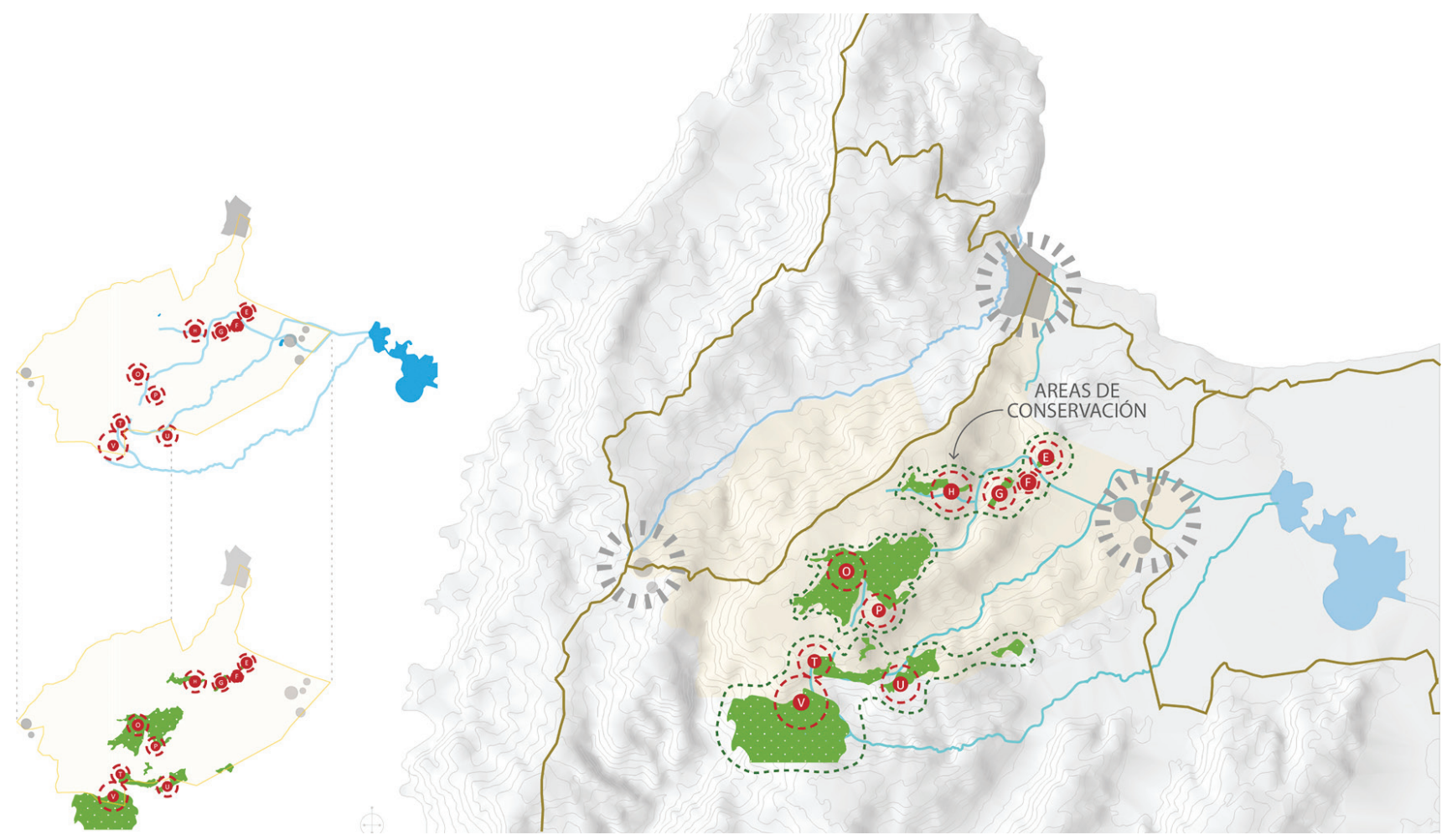

Figura 11. Estrategias de conservación y re-naturalización (fuente: Elaboración propia 2016). 


\section{CONCLUSIONES.}

Nos encontramos frente a un escenario cuyo paisaje cultural mapuche, a pesar de haber experimentado un proceso de destrucción y desvalorización, todavía es capaz de reflejar la historia de sus comunidades. La apropiación de los territorios ancestrales y la expansión indiscriminada de las plantaciones forestales han ocasionado una serie de problemáticas sociales y territoriales, desvinculando así al mapuche de su territorio natural.

Frente este escenario, se formula una serie de estrategias y acciones que hacen posible una revalorización del paisaje cultural mapuche.

Se define entonces, una primera estrategia que establece tres áreas de acción, donde Llico se presenta como la localidad que posee un mayor número de valores enfocados a la cultura mapuche, lo que deriva en una segunda estrategia que busca revalorizar el paisaje cultural. Para ello, se consideran al menos tres acciones que permiten poner en valor el territorio: la creación de puertas para determinar la entrada al territorio mapuche la definición de recorridos públicos y privados, que integran, organizan y conectan los elementos de significación cultural; y la determinación de áreas de conservación ecológica que protegen el desarrollo de la naturaleza nativa.

De esta forma, la intención de otorgar una respuesta a la revalorización del paisaje cultural mapuche cobra sentido. El reordenamiento e integración de los elementos que componen el paisaje cultural, permiten recuperar y potenciar la identidad territorial de sus comunidades. $\mathbf{\Delta} \boldsymbol{0}$

\section{REFERENCIAS}

Aylwin, J., 2002. Tierra y territorio mapuche: Un análisis desde una perspectiva histórico juridica. Temuco: Instituto de Estudios Indigenas, Universidad de La Frontera

Aylwin, J., 2000. Los conflictos en el territorio mapuche: Antecedentes y perspectivas. Santiago de Chile: Universidad de Chile, Departamento de Ingeniería Industrial.

Aylwin, J., 1995. Estudio sobre tierras indígenas de la Araucanía: Antecedentes Histórico Legislativos (18501920). Temuco, Chile: Instituto de Estudios Indigenas, Universidad de la Frontera.

Bengoa, J., 1996. Historia del pueblo mapuche (Siglo XIX y XX). Santiago de Chile: Ediciones sur.

Bonet, J., 2014. "El movimiento mapuche en Chile: de la reivindicación por la tierra al reconocimiento como pueblo." Anuario de Movimientos Sociales 2013. Disponible en: http://fundacionbetiko.org/wp-content/ uploads/2014/03/Elmovimiento-mapuche-en-Chilepdf

Busquets, J., 2009. Gestión del paisaje: Manual de protección, gestión y ordenación del paisaje. España: Editorial Ariel.

Calbucura, J. y Le Bonniec, F., (Eds.), 2009. Territorio y territorialidad en contexto post-colonial. Estado de Chile: Nación mapuche. Working Paper Series 30 Ñuke Mapuförlage

Comisión Nacional del Medio Ambiente - CONAMA, 1997. Informe Técnico del Estudio de Impacto Ambiental del Proyecto "Central Hidroeléctrica Ra/co". Chile: Empresa Nacional de Electricidad S.A.

Correa, M., Yánez, N. y Molina, R., 2005. La Reforma Agraria y Las Tierras Mapuches: Chile 1962-1975. Santiago de Chile: LOM Ediciones

CENSO 2002. Santiago de Chile: Instituto Nacional de Estadísticas. Ministerio de Planificación Nacional. Corporación Nacional Forestal - CONAF, 2013. Por un Chile forestal sustentable. Santiago de Chile: Editora Zigzag.

Frías, G., 2003. Invasión Forestal. Khla Nagnegei Taiñ weichangepan. Canadá: Centro Internacional de Investigaciones para el Desarrollo (IDRC). Disponible en: http://wrm.org.uy/oldsite/paises/Chile/Lumako.pdf Gavilán, V., 2002. La República de Chile y los mapuches (1810-1881). Actas del Primer Congreso Internaciona de Historia Mapuche. Nuke Mapuförlaget. Disponible en: http://www.mapuche.info/mapuint/contreras070701.pdf Gedda, M., 2010. Patrimonio de la Araucania-Chile. Manual de interpretación y puesta en valor. Villarrica: Pontificia Universidad Católica de Chile.

Hernández, M., 2009. "El paisaje como seña de identidad territorial: valorización social y factor de desarrollo, ¿utopia o realidad?" Boletín de la Asociación de Geógrafos Españoles, 49: 169-183. Ibarra, M., 2008. "Lo mapuche dentro de la identidad chilena: Doble discurso." Historia Actual Online, 1: 1-20. Iglesias, A. y González, J., 2013. Una mirada histórica desde las voces de Llico. Hogar de Cristo y América Solidaria
Imilan, W. y Álvarez, V., 2008. "El pan mapuche. Un acercamiento a la migración mapuche en la ciudad de Santiago." Revista Austral de Ciencias Sociales, 14: 23-49

Instituto Nacional de Estadisticas (INE), 2003. Censo 2002. Sintesis de Resultados. Santiago de Chile: Ministerio de Planificación Nacional, Gobierno de Chile.

Jara. A., 1971. Guerra y sociedad en Chile. La transformación de la guerra de Arauco y la esclavitud de los indios. Santiago de Chile: Editorial Universitaria.

Lynch, K. 1964. La imagen de la ciudad. Barcelona: Gustavo Gili Editores.

Lincopi, L., 2016. Entrevista personal. Localidad de Llico, Chile.

Maderuelo, J., 2010. Paisaje y Patrimonio. Madrid: Abada Editores.

Maderuelo. J., 2005. El paisaje: génesis de un concepto. Madrid: Abada Editores.

Mata, R., 2008. "El paisaje, patrimonio y recurso para el desarrollo territorial sostenible. Conocimiento y acción pública." ARBOR, Ciencia, Pensamiento y Cultura, 729: 155-172

Memoria Chilena, s/f. //ustración del Parlamento de Quilin entre hispanos e indios. Biblioteca Nacional de Chile. Disponible en: http://www.memoriachilena.gob.cl/602/w3-article-100463.html

Montalba, R., Carrasco, N., Araya, J., 2005. Contexto económico y social de las plantaciones forestales en chile. El caso de Lumaco región de la Araucanía. Chile: Movimiento mundial por los bosques tropicales. Chile: Observatorio Latinoamericano de Conflictos ambientales (OLCA).

Museo Chileno de Arte Precolombino, 2009. Riqueza y Guerra. Disponible en: http://www.precolombino.cl/ wp/wp-content/uploads/2009/05/riqueza-y-guerra.pdf

Naveh, Z. 2000. "What is holistic landscape ecology? A conceptual introduction." Land and Urb Plan, 50 $7-26$

Pinto, J., 1992. "Crisis Económica y Expansión Territorial: La ocupación de la Araucanía en la segunda mitad del siglo XIX." Estudios Sociales, 72.

Schama, S., 1995. Landscape and Memory. Nueva York: Alfred A. Knopf.

Stephens, J., 2002. "The Formation of Place and Identity." Urban Policy and Research, 20 (1): 87-99. Triviños, G., 2003. "Revisitando la literatura chilena: 'Sigue diciendo: cayeron / Di más: volverán mañana'." Atenea, 487: 113-133. Disponible en: https://scielo.conicyt.cl/scielo.php?pid=S071804622003048700009\&script=sci arttext

Zoido, F, 2008. "Los geógrafos y la ordenación del territorio. Alguna reflexiones sobre sus relaciones en España." En Artigue, A. Blázquez-Salom, M., Murray, I. y Rullán, O. (Eds.) Albert Quintana. El seu temps i la seva obra. Mallorca: Dirección General de Ordenación del Territorio, Gobierno de Islas Baleares, 474-489. 